\title{
Quality Control
}

National Cancer Institute

\section{Source}

National Cancer Institute. Quality Control. NCI Thesaurus. Code C15311.

Set of measurements and inspections taken to verify that performance of equipment and procedures remains within specified limits. 